\title{
Editorial
}

\section{Proceedings of the XXIX GIRI meeting}

Saurav Arora

The day is not far when ultra-high dilutions would have their acceptance within conventional realm of physics, chemistry and biology!

High dilution experiments and homeopathy are on verge of being accepted within conventional scientific norms. Various authorities and scientists are now keen to explore nature and behaviour of UHDs. This may be well perceived by the growing number or publications and self-help groups of researchers. One such example is the Groupe International de Recherche sur I'Infinitésimal (GIRI) (www.giriweb.com).

GIRI was founded in 1986 by Prof. Madeleine Bastide. Bastide, Professor of Immunology at University of Montpellier, was amongst the most remarkable personalities in homeopathic research. ${ }^{1}$ GIRI was "originated" from seminars on alternative medicine organized by Princess Antoinette of Monaco during 1980s.

Today, GIRI represents one of the most relevant and independent scientific, not-forprofit international organizations dedicated to study high dilutions and homeopathy. GIRI has been succeeded to a greater extent in undertaking experimentation on high dilution aspects and homeopathy by a wellconnected network of researchers.

GIRI aims to bring together pharmacologists, biologists, physicians, chemists, physicists and other professionals to exchange expertise and knowledge. This technical liaison has opened up many frontiers in homeopathy.

Since beginning GIRI has been organizing workshops and annual meetings to keep its members connected and updated, and also, to define strategies of collaboration between the different researchers in different countries.

This year GIRI organized its XXIX meeting at University of Verona, Italy on $3-4^{\text {th }}$ June 2015. The University of Verona, founded in 1982, and is amongst one of the best universities of Italy. It is dedicated to innovation and to maintaining the high quality of its teaching and research. Many researchers from University are part of GIRI.

The XXIX symposium aimed at gathering and disseminating the most recent experience of researchers engaged in fundamental and basic research (biological, chemical and physical models); effects of high dilutions on agronomy, veterinary; clinical research on drugs used in homoeopathic, homotoxicological and anthroposophical medicines, etc.

The symposium witnessed some of the key researchers from all over the world, who presented their work. There were detailed deliberations on various aspects of research.

The current issue of IJHDR features selected abstracts which were presented during the XXIX GIRI symposia. The abstracts have been categorized according to type of research. In total 28 abstracts have been paginated which includes research work on agronomy, veterinary, leishmaniasis, droplet evaporation method, mice models, cancer, malaria, reviews etc.

Further, this issue features open access compendium of IJHDR articles published during 2008 - 2014, which may be saved to any media and serve as a handy material of all articles published in IJHDR during this period.

OPEN ACCESS

Cite as: Arora S. Proceedings of the XXIX GIRI Meeting; 2015 June 3 - 5; Verona (Italy). Int J High Dilution 
Proceedings of the XXIX GIRI Meeting; 2015 June 3 - 5; Verona (Italy). International Journal of High Dilution Research 2015; 14(2):1-2 Available online at www. highdilution.org

Readers' valuable suggestions and References comments are welcome.

1. Bonamin LV. Madeleine Bastide [Obituaries]. 2007;96:287-289

(C) International Journal of High Dilution Research.

Not for commercial purposes. 